\title{
Crystal Defects and Cation Redistribution Study on Nanocrystalline Cobalt-Ferri-Chromites by Positron Annihilation Spectroscopy
}

\author{
Kunal B. Modi, ${ }^{1}$ Nimish H. Vasoya, ${ }^{2}$ Vinay K. Lakhani, ${ }^{3}$ \\ Tushar K. Pathak, ${ }^{4}$ and P. M. G. Nambissan ${ }^{5}$ \\ ${ }^{1}$ Department of Physics, Saurashtra University, Rajkot, Gujarat 360005, India \\ ${ }^{2}$ Om Shanti Engineering College, Morbi Road, Rajkot, Gujarat 360030, India \\ ${ }^{3}$ Department of Physics, Bahauddin Science College, Junagadh, Cujarat 362001, India \\ ${ }^{4}$ Government Engineering College, Kalawad Road, Rajkot, Gujarat 360005, India \\ ${ }^{5}$ Applied Nuclear Physics Division, Saha Institute of Nuclear Physics, Kolkata, West Bengal 700064, India
}

Correspondence should be addressed to Kunal B. Modi; kunalbmodi2003@yahoo.com

Received 5 March 2013; Accepted 7 May 2013

Academic Editor: Hicham Fenniri

Copyright (C) 2013 Kunal B. Modi et al. This is an open access article distributed under the Creative Commons Attribution License, which permits unrestricted use, distribution, and reproduction in any medium, provided the original work is properly cited.

\begin{abstract}
Positron lifetime and Doppler broadening measurements were carried out on nanocrystalline (grain size $\sim 60-65 \mathrm{~nm}$ ) samples of the $\mathrm{Cr}^{3+}$-substituted cobalt ferrite system with general chemical formula $\mathrm{CoCr}_{x} \mathrm{Fe}_{2-x} \mathrm{O}_{4}(x=0.0-2.0)$ synthesized by the coprecipitation technique. The results indicated selective trapping of positrons in large vacancy clusters initially at the tetrahedral (A-) sites and then with $\mathrm{Cr}^{3+}$-substitution up to concentration $(x)=0.7$, at the octahedral (B-) sites. The results are consistent with the cation distribution determined from X-ray diffraction line intensity calculations, which indicated partial inversion of the inverse spinel ferrite, subsequent stabilization over a range of substitution ( $x=0.7$ to 1.7 ), and finally the full inversion to the normal spinel chromite $\left(\mathrm{CoCr}_{2} \mathrm{O}_{4}, x=2.0\right)$. In the intermediate range of substitution, lattice contraction prevented a fraction of $\mathrm{Co}^{2+}$ ions released from the (B-) sites from entering the tetrahedral sites, and these vacancies at the (A-) sites trapped positrons. Although the samples were composed of nanocrystalline grains, only an insignificant fraction of positrons were diffused and annihilated at the grain surfaces, since the grain sizes and the thermal diffusion length of positrons nearly overlapped.
\end{abstract}

\section{Introduction}

Crystalline materials with the characteristic spinel structure, comprising of well-designated tetrahedral (A-) and octahedral (B-) sites, constitute a very interesting class of condensed matter systems evoking interest even from the very fundamental science viewpoint $[1,2]$. Cobalt ferrite $\left(\mathrm{CoFe}_{2} \mathrm{O}_{4}\right)$, Cobalt chromite $\left(\mathrm{CoCr}_{2} \mathrm{O}_{4}\right)$, and their solid solutions with a typical crystalline structure $\mathrm{XY}_{2} \mathrm{O}_{4}$ are candidate materials in this class, where $\mathrm{X}$ is normally a divalent and $\mathrm{Y}$ is a trivalent ion. These materials have attracted a large number of chemists, physicists, and metallurgists to study their different aspects, including the structure and properties, using both theoretical modeling and wide variety of experimental tools [3-5]. Ferrites composed of nanometer-sized particles elevate this interest to new dimensions as the very large network of interfaces will then play a decisive role in controlling the atomic transport and spatial rearrangement of atoms within the structure. So far as the tools for investigating such details are concerned, conventional experimental methods such as X-ray diffraction (XRD) and transmission electron microscopy (TEM) have helped to obtain substantial information on a macroscopic scale. But defect-specific probes such as positron annihilation spectroscopy are needed to pinpoint their role in the postsynthesis and characterization treatments such materials have to undergo. We present in this paper the results of our investigation carried out on $\mathrm{CoFe}_{2} \mathrm{O}_{4}$, both on the nascent mother sample and samples in which the $\mathrm{Fe}^{3+}$ ions are replaced by $\mathrm{Cr}^{+3}$ ions, that is, $\mathrm{CoCr}_{x} \mathrm{Fe}_{2-x} \mathrm{O}_{4}, x=$ $0.0-2.0$. The purpose of the work is double sided. Initially we 
will present the important observations which were obtained from more conventional experimental tools such as XRD, TEM, and energy dispersive analysis of X-rays (EDAX) and highlight the changes occurring at the different stages of $\mathrm{Cr}^{3+}$-substitution. The emphasis will be thereafter diverted to demonstrate the ability of positron annihilation techniques to sense such changes. The latter is of importance since such works are scarcely available in the literature so far, and secondly it offers a viable investigative probe for such studies which are highly essential in the current scenario of novel materials and arising challenges in their understanding.

According to the existing literature, cobalt ferrite $\left(\mathrm{CoFe}_{2} \mathrm{O}_{4}\right)$ is an inverse spinel and taken to be collinear ferrimagnet [6], while cobalt chromite, $\mathrm{CoCr}_{2} \mathrm{O}_{4}$, is a normal spinel with a canted ferromagnetic structure, and its Curie temperature is $97 \mathrm{~K}$ [7]. Previous studies of magnetic properties and Mossbauer spectroscopy on mixed cobaltferri-chromites, $\mathrm{CoCr}_{x} \mathrm{Fe}_{2-x} \mathrm{O}_{4}$, of coarse-grain composition indicated that canting of magnetic structure is observed when $\mathrm{Co}^{2+}$ is present at the tetrahedral (A-) site $[8,9]$. While magnetization measurements on the same system could be explained by Neel's model as far as the series remained inverse spinel, they deviated significantly when they began to have normal spinel structure [10]. Recently, structural and magnetic properties of nanocrystalline $\mathrm{CoCr}_{x} \mathrm{Fe}_{2-x} \mathrm{O}_{4}(0 \leq x$ $\leq 1.0)$ system prepared by the sol-gel autocombustion route have been studied by Tolesha et al. [11].

The redistribution of cations when one species is replaced by ions of neighboring elements in the periodic table has been of tremendous significance in modifying the properties as well as in giving rise to new phenomena and processes [6, $8,9]$. The transformation of a nearly complete inverse spinel ferrite, $\mathrm{CoFe}_{2} \mathrm{O}_{4}$, to a normal spinel chromite, $\mathrm{CoCr}_{2} \mathrm{O}_{4}$, through successive replacement of the $\mathrm{Fe}^{3+}$ ions by $\mathrm{Cr}^{3+}$ ions has been found to generate drastic changes in the cationic distribution in the structure, owing to lattice contraction as well as the likely presence of vacancy-type structural defects. Although substitution effects generally prompt such redistributions, concomitant lattice contraction or expansion can also influence it, and quite often it will result in the generation of structural defects in the form of unoccupied lattice sites. The latter are potential sites for investigation by positron annihilation experiments. Such a defect-sensitive spectroscopic probe will be of immense benefit as it can pinpoint the origin and evolution of such defects and their dominating role over the redistribution of ions in the lattice. As is popularly known, the positron lifetimes and Doppler broadening of the electron-positron annihilation gamma ray spectrum are directly related to the electron density and momentum distribution in a material, and hence, the information carried by the signals of annihilation can unravel the material properties in the atomic scale [12].

\section{Experimental Procedure}

The spinel ferrite system, $\mathrm{CoCr}_{x} \mathrm{Fe}_{2-x} \mathrm{O}_{4}$, with variable compositions with the range of $x=0.0,0.1,0.3,0.7,1.1,1.3$, $1.5,1.7,1.8,1.9$, and 2.0 were prepared by air oxidation of an aqueous suspension containing $\mathrm{Co}^{2+}, \mathrm{Fe}^{2+}$, and $\mathrm{Cr}^{3+}$ cations in stoichiometric proportions. The starting solutions was prepared by mixing $50 \mathrm{~mL}$ of aqueous solutions of $\mathrm{CoSO}_{4} \cdot 7 \mathrm{H}_{2} \mathrm{O}, \mathrm{FeSO}_{4} \cdot 7 \mathrm{H}_{2} \mathrm{O}$, and $\mathrm{Cr}_{2}\left(\mathrm{SO}_{4}\right)_{3} \cdot 6 \mathrm{H}_{2} \mathrm{O}$ in proper proportions. A $2 \mathrm{M}$ solution of $\mathrm{NaOH}$ was prepared as a precipitant. The starting solution $(\mathrm{pH} \sim 3.5)$ was added into the precipitant so that the solubility product constants for the hydroxides of the cation are exceeded and their sequential precipitation can be avoided. The suspension $(\mathrm{pH}=10.5)$ thus formed, containing dark green intermediate precipitates, was then heated and kept at $333 \mathrm{~K}$ for 1 hour. During the heating, oxygen gas was bubbled uniformly into the suspension to stir it and to promote oxidation reaction until all the intermediate precipitates changed into dark brownish precipitates of the spinel ferrite. The samples were filtered, washed by acetone several times, and dried at $473 \mathrm{~K}$ under vacuum.

The formation of the ferrite powders by the oxidation method consists of oxidation by air $\left(\mathrm{O}_{2}\right)$ bubbling through an aqueous solution containing ferrous ions $\left(\mathrm{Fe}^{2+}\right)$ and other divalent ions $\left(\mathrm{M}^{2+}\right)$ after an alkaline solution $(\mathrm{ROH})$ has been added. This is according to the chemical reaction $\mathrm{Fe}^{2+}+$ $\mathrm{M}^{2+}+\mathrm{ROH}+\mathrm{O}_{2} \rightarrow \mathrm{M}^{2+}\left(\mathrm{Fe}^{3+}\right)_{2} \mathrm{O}_{4}$ where $\mathrm{ROH}$ is $\mathrm{NaOH}$, $\mathrm{KOH}, \mathrm{NH}_{4} \mathrm{OH}$, and so forth. Ferrite powder of high homogeneity and purity and with sufficient control over the particle size can be achieved by this method.

The stoichiometry of the powdered samples was confirmed from EDAX measurements. The compositional values were determined within an accuracy of $1 \%$. X-ray diffraction data were collected using a Philips (PW 1710) automated $\mathrm{X}$-ray powder diffractometer with $\mathrm{Cu} \mathrm{K}_{\alpha}$ radiation, graphite monochromator, and Xe-filled proportional counter. Data were collected in the angle range $5^{\circ}-80^{\circ}$. TEM images of the samples were taken using a TECNAIK 20 (Philips) microscope operated at $200 \mathrm{kV}$. For the TEM observations, the powder was first dispersed in amyl acetate by ultrasonication, and then the suspensions were dropped on a copper grid with a carbon film. The grain sizes and shapes were determined from the TEM pictures.

Positron annihilation studies of the powdered samples were performed in the conventional way. The radioactive isotope ${ }^{22} \mathrm{Na}$ in the form of ${ }^{22} \mathrm{NaCl}$ dissolved in dilute $\mathrm{HCl}$ was deposited and dried on a thin $(\sim 2 \mu \mathrm{m}) \mathrm{Ni}$ foil and folded to form the source of positrons. It was kept immersed in the volume of the sample taken in a glass tube. Care was taken to ensure that the powdered sample surrounded the source from all sides sufficiently enough to ensure annihilation of positrons within it. Further, the sample with the source embedded in it was maintained under dry vacuum conditions during the experiments. This is done to eliminate the possibility of the trapping of positrons and quenching of positronium (the metastable bound state of the positron and an electron) by the air and gases otherwise getting trapped within the powdered sample [13]. The positron lifetime measurements were carried out using a slow-fast coincidence spectrometer, having a time resolution (FWHM) of $200 \mathrm{ps}$ for the gamma rays from ${ }^{60} \mathrm{Co}$ source under experimental conditions. For Doppler broadening measurements, a high pure germanium (HPGe) detector with resolution $1.14 \mathrm{keV}$ 
at $511 \mathrm{keV}$ was used. This and another detector with identical resolution were used on either side of the source-sample assembly for coincidence Doppler broadening spectroscopy (CDBS) studies. The CDBS experiments helped to identify the elemental environment around the positron trapping sites in materials by virtue of the ability to record the gamma ray energy distribution spectra of positron annihilation with the high momentum core electrons, without the nuclear background. The details about these measurements and the methods of data analysis to extract the relevant information can be seen in the paper by Asoka-Kumar et al. [14].

\section{Results and Discussion}

3.1. Characterization of the Samples. After obtaining the final products, it was essential to check the chemical composition of each sample. The reason for making EDAX characterization was to ratify the purity and surety of the chemical composition. Two representative EDAX patterns, namely, of $x=0.3$ and 1.8 compositions are shown in Figure 1. The results of EDAX confirm the expected stoichiometry with small deficiencies of $\mathrm{Cr}^{3+}$ ions. Further, the incorporation of $\mathrm{Cr}^{3+}$ in the place of $\mathrm{Fe}^{3+}$ was indicated by the intensities of the respective peaks in the two patterns. No traces of impurities were found. The EDAX results suggested that the precursors had fully undergone the chemical reaction to form ferrite material of the expected composition.

The particle size and morphology of all the compositions were studied by means of transmission electron microscopy. Typical images for $x=0.0,1.0$, and 1.6 compositions are shown in Figure 2. It can be seen that the average particle size is in the range $60-65 \mathrm{~nm}$.

The $\mathrm{CoCr}_{x} \mathrm{Fe}_{2-x} \mathrm{O}_{4}$ samples were characterized by XRD to ascertain the single-phase structure formation and to deduce cell edgeparameter and cation distribution and grain size verification. Typical XRD patterns of $\mathrm{CoCr}_{x} \mathrm{Fe}_{2-x} \mathrm{O}_{4}$ samples with $x=0.0,0.7,1.1,1.3,1.7$, and 2.0 are shown in Figure 3 . The background noise and the broadness of the peaks are characteristics of particles with nanometer dimensions since there is not a sufficient number of crystallographic planes to result in sharp diffraction lines. The XRD patterns also showed that all the samples have the monophase spinel structure. No extra lines corresponding to any other phase or nonreacted ingredients were detected. The diffraction patterns could be indexed for a face centered cubic (fcc) structure [15]. The lattice constant for each composition was determined by using the "Powder-X" software [16]. The concentration dependence of the lattice constant $(a)$ determined from the X-ray data is presented in Figure 4. The lattice constant remains more or less constant initially but rapidly decreases for higher concentrations of $\mathrm{Cr}^{3+}$. The observed change in lattice constant value with $\mathrm{Cr}^{3+}$-content $(x)$ is attributed to the small difference in the ionic radii of the constituent cations, $\mathrm{Fe}^{3+}(0.640 \AA)$ and $\mathrm{Cr}^{3+}(0.630 \AA)$, and the change in the distribution of cations among the available (A-) and (B-) sites of the spinel lattice.

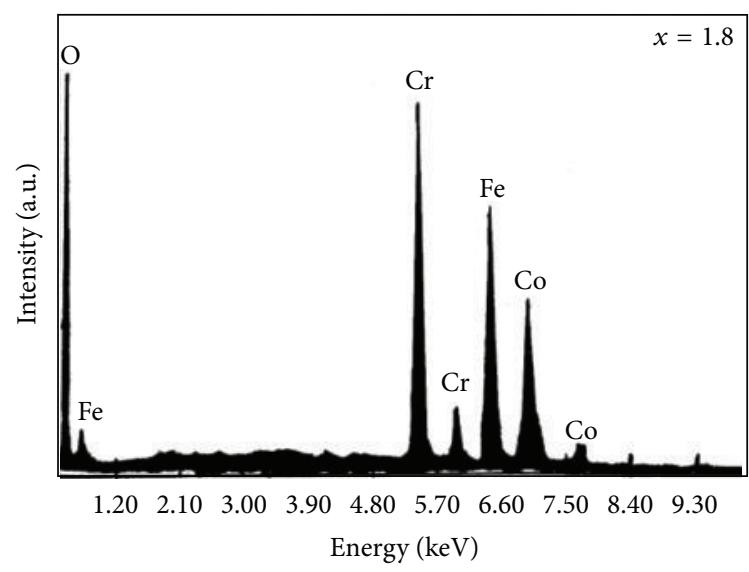

(a)

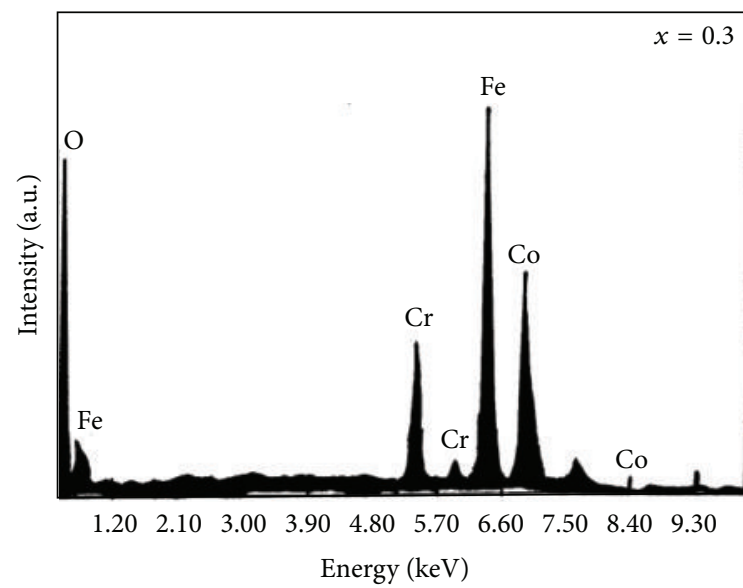

(b)

FIgURE 1: The EDAX spectrum of the $\mathrm{Cr}^{3+}$-substituted samples, at concentrations $x=0.3$ and 1.8 .

In order to determine the cation distribution, the XRD line intensity calculations were made using the formula suggested by Buerger [17]:

$$
I_{h k l}=\left|F_{h k l}\right|^{2} P L .
$$

Here, $I_{h k l}$ is the relative integrated intensity, $F_{h k l}$ is the structure factor, $P$ is the multiplicity factor, and $L=(1+$ $\left.\cos ^{2} 2 \theta\right) /\left(\sin ^{2} \theta \cos \theta\right)$ is the Lorentz polarization factor.

According to Ohnish and Teranishi [18], the intensity ratios of planes $I_{220} / I_{440}$ and $I_{400} / I_{422}$ are considered to be sensitive to the cation distribution. There exists distinct contrast in the atomic scattering factors of $\mathrm{Cr}^{3+}$ or $\mathrm{Fe}^{3+}$ and $\mathrm{Co}^{2+}$ cations present in the system. This makes the determination of the cation distribution quite reliable. Any alteration in the distribution of cations causes a significant change in the XRD intensity ratios. Therefore, in the process of arriving at the final cation distribution, the site occupancy of all the cations was varied for many combinations, and those that agreed with the experimental intensity ratios are shown in Table 1. The final cation distributions were deduced simultaneously by considering the Bragg plane ratios, the fitting of the magnetization data at $80 \mathrm{~K}$, and the ion distribution 


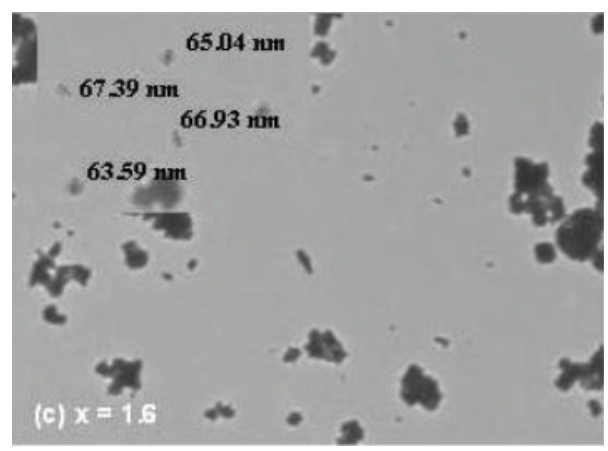

(a)

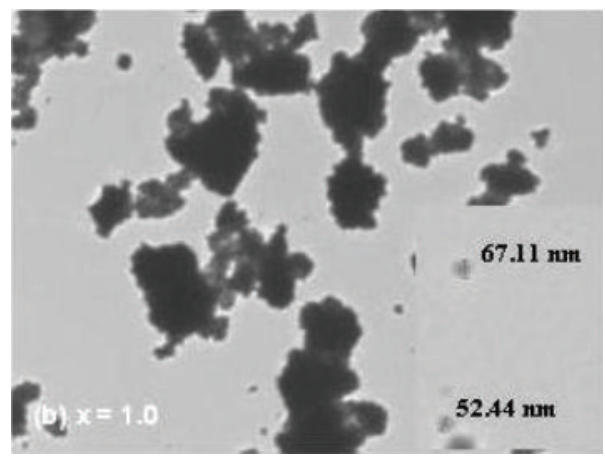

(b)

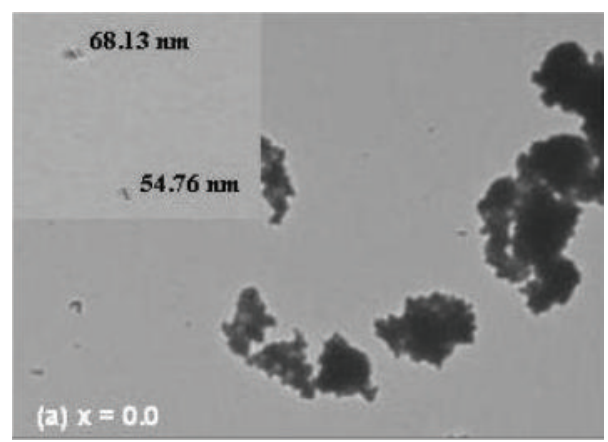

(c)

FIgURE 2: Transmission electron micrographs of $\mathrm{CoCr}_{x} \mathrm{Fe}_{2-x} \mathrm{O}_{4}$ system for (a) $x=0.0$, (b) 1.0 , and (c) 1.6 compositions. The insets show the enlarged images of grains in each case.

parameters of $\mathrm{Fe}^{3+}$ among the (A-) and (B-) sites of spinel lattice derived from Mossbauer spectral analysis [19].

3.2. Positron Lifetimes in the Unsubstituted Sample, $\mathrm{CoFe}_{2} \mathrm{O}_{4}$ $(x=0.0)$. The positron lifetime spectra were analyzed using the PALSfit computer program developed by the Risoe group [20]. The spectra of all the samples were fitted to obtain variances of fit within satisfactory limits $(1.07 \pm 0.12)$. The fits yielded three distinct lifetimes $\tau_{1}, \tau_{2}$, and $\tau_{3}$ in all the cases, and their magnitudes, as discussed below, were the characteristics of positron trapping in specific sites within the spinel structure or positronium formation within the grain boundaries. In the $\mathrm{CoFe}_{2} \mathrm{O}_{4}(x=0.0)$ sample, the intermediate lifetime $\tau_{2}$ was found as high as $356 \mathrm{ps}$ with relative intensity $I_{2}=48.2 \%$. The normal interpretation
TABLE 1: The cationic distribution in the samples at different $\mathrm{Cr}^{3+}$ concentrations $(x)$

\begin{tabular}{ll}
\hline$x$ & Cation distribution \\
\hline 0.0 & $\left(\mathrm{Fe}^{3+}{ }_{0.9} \mathrm{Co}^{2+}{ }_{0.1}\right)^{\mathrm{A}}\left[\mathrm{Co}^{2+}{ }_{0.9} \mathrm{Fe}^{3+}{ }_{1.1}\right]^{\mathrm{B}} \mathrm{O}_{4}{ }^{2-}$ \\
0.1 & $\left(\mathrm{Fe}^{3+}{ }_{0.8} \mathrm{Co}^{2+}{ }_{0.2}\right)^{\mathrm{A}}\left[\mathrm{Co}^{2+}{ }_{0.8} \mathrm{Cr}^{3+}{ }_{0.1} \mathrm{Fe}^{3+}{ }_{1.1}\right]^{\mathrm{B}} \mathrm{O}_{4}{ }^{2-}$ \\
0.3 & $\left(\mathrm{Fe}^{3+}{ }_{0.6} \mathrm{Co}^{2+}{ }_{0.4}\right)^{\mathrm{A}}\left[\mathrm{Co}^{2+}{ }_{0.6} \mathrm{Cr}^{3+}{ }_{0.3} \mathrm{Fe}^{3+}{ }_{1.1}\right]^{\mathrm{B}} \mathrm{O}_{4}{ }^{2-}$ \\
0.7 & $\left(\mathrm{Fe}^{3+}{ }_{0.3} \mathrm{Co}^{2+}{ }_{0.7}\right)^{\mathrm{A}}\left[\mathrm{Co}^{2+}{ }_{0.3} \mathrm{Cr}^{3+}{ }_{0.7} \mathrm{Fe}^{3+}{ }_{1.0}\right]^{\mathrm{B}} \mathrm{O}_{4}{ }^{2-}$ \\
1.1 & $\left(\mathrm{Fe}^{3+}{ }_{0.3} \mathrm{Co}^{2+}{ }_{0.7}\right)^{\mathrm{A}}\left[\mathrm{Co}^{2+}{ }_{0.3} \mathrm{Cr}^{3+}{ }_{1.1} \mathrm{Fe}^{3+}{ }_{0.6}\right]^{\mathrm{B}} \mathrm{O}_{4}{ }^{2-}$ \\
1.3 & $\left(\mathrm{Fe}^{3+}{ }_{0.3} \mathrm{Co}^{2+}{ }_{0.7}\right)^{\mathrm{A}}\left[\mathrm{Co}^{2+}{ }_{0.3} \mathrm{Cr}^{3+}{ }_{1.3} \mathrm{Fe}^{3+}{ }_{0.4}\right]^{\mathrm{B}} \mathrm{O}_{4}{ }^{2-}$ \\
1.5 & $\left(\mathrm{Fe}^{3+}{ }_{0.3} \mathrm{Co}^{2+}{ }_{0.7}^{\mathrm{A}}\left[\mathrm{Co}^{2+}{ }_{0.3} \mathrm{Cr}^{3+}{ }_{1.5} \mathrm{Fe}^{3+}{ }_{0.2}\right]^{\mathrm{B}} \mathrm{O}_{4}{ }^{2-}\right.$ \\
1.7 & $\left(\mathrm{Fe}_{0.3}^{3+} \mathrm{Co}^{2+}{ }_{0.7}\right)^{\mathrm{A}}\left[\mathrm{Co}^{2+}{ }_{0.3} \mathrm{Cr}^{3+}{ }_{1.1}\right]^{\mathrm{B}} \mathrm{O}_{4}{ }^{2-}$ \\
1.8 & $\left(\mathrm{Co}^{2+}{ }_{1.0}\right)^{\mathrm{A}}\left[\mathrm{Cr}^{3+}{ }_{1.8} \mathrm{Fe}^{3+}{ }_{0.2}\right]^{\mathrm{B}} \mathrm{O}_{4}^{2-}{ }^{2-}$ \\
1.9 & $\left(\mathrm{Co}^{2+}{ }_{1.0}\right)^{\mathrm{A}}\left[\mathrm{Cr}^{3+}{ }_{1.9} \mathrm{Fe}^{3+}{ }_{0.1}\right]^{\mathrm{B}} \mathrm{O}_{4}{ }^{2-}$ \\
2.0 & $\left(\mathrm{Co}^{2+}{ }_{1.0}\right)^{\mathrm{A}}\left[\mathrm{Cr}^{3+}{ }_{2.0}^{\mathrm{B}}\right]^{\mathrm{B}} \mathrm{O}_{4}{ }^{2-}$ \\
\hline
\end{tabular}

for the observation of such a well-resolved longer lifetime with appreciable intensity is the presence of vacancy-type crystalline defects within the material since positrons get trapped in such lower-than-average-electron-density sites. This is a reasonable assumption since it is nearly impossible to synthesize ferrites with fully occupied crystalline structure. Besides, those positrons managing to diffuse out to the vacancies on the nanocrystalline grain interfaces may also contribute to this component. The reason is that the thermal diffusion lengths of positrons in oxide materials are typically about 50-60 nm [21, 22]. Hence, a small fraction of positrons would inevitably diffuse and migrate to the surfaces of the nanocrystals (which are of sizes about 60-65 nm) before their annihilation. Despite prolonged heating, the grain dimensions could not be increased to more than the above limit. On the other hand, the diffusion lengths in the present case could be shortened due to the trapping of positrons by vacancy clusters if present within the nanoparticles. The positron lifetime in the perfect crystalline sample $\left(\tau_{f}\right.$, for which no theoretical value is available) can be calculated using the trapping model equation [23]:

$$
\frac{1}{\tau_{f}}=\frac{I_{1}}{\tau_{1}}+\frac{I_{2}}{\tau_{2}}+\frac{I_{3}}{\tau_{3}}
$$

Substituting the experimental values of the positron lifetimes and their intensities of the $\mathrm{CoFe}_{2} \mathrm{O}_{4}$ sample in the above equation, we obtain $\tau_{f}=199 \mathrm{ps}$. The shorter lifetime component $\tau_{1}$ is obviously less than this value in all the cases due to admixing with the Bloch state residence time of trapped positrons [12]. A small contribution coming to $\tau_{1}$ from parapositronium atoms of lifetime $125 \mathrm{ps}$ is ignored as the intensity of this component, one-third that of the orthopositronium intensity $I_{3}$, is negligibly small.

The annihilation characteristics of positrons diffusing out to the grain surfaces are also reflected in the variation of the longest lifetime $\tau_{3}$ and its intensity $I_{3}$. The magnitude of this lifetime (1.8-2.1 ns) is typical of the "pick-off" annihilation of orthopositronium atoms formed at the interfacial regions of the grains [12]. Although positronium formation is not significant enough to alter the interpretations in metallic oxides, it has been found still relevant enough to force a 


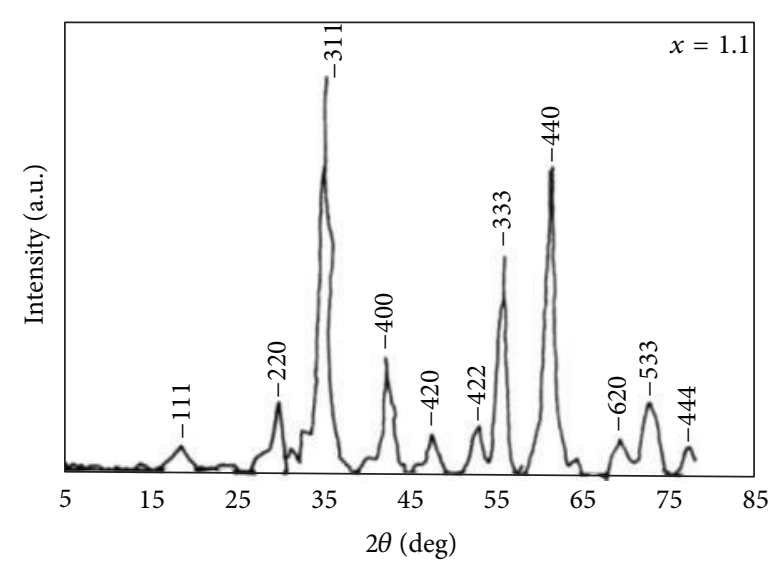

(a)

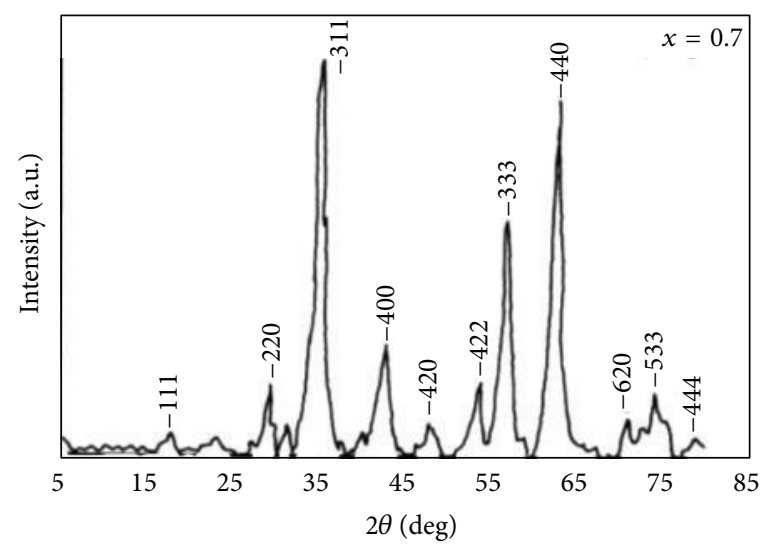

(c)

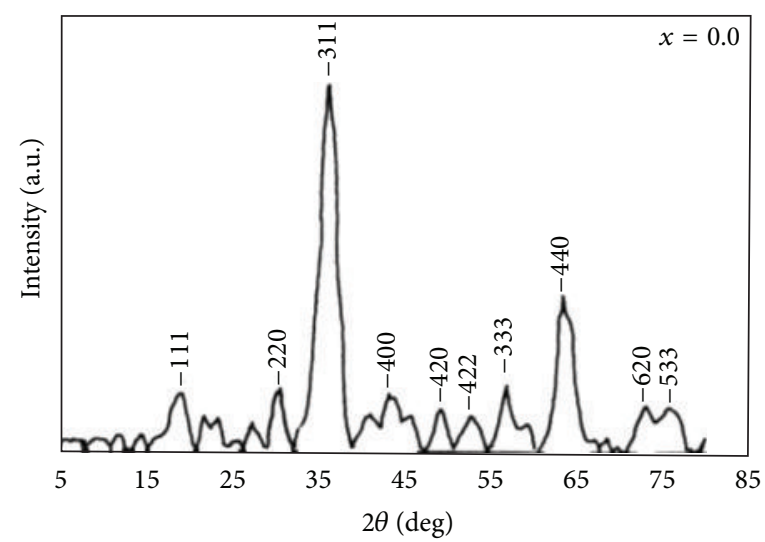

(e)

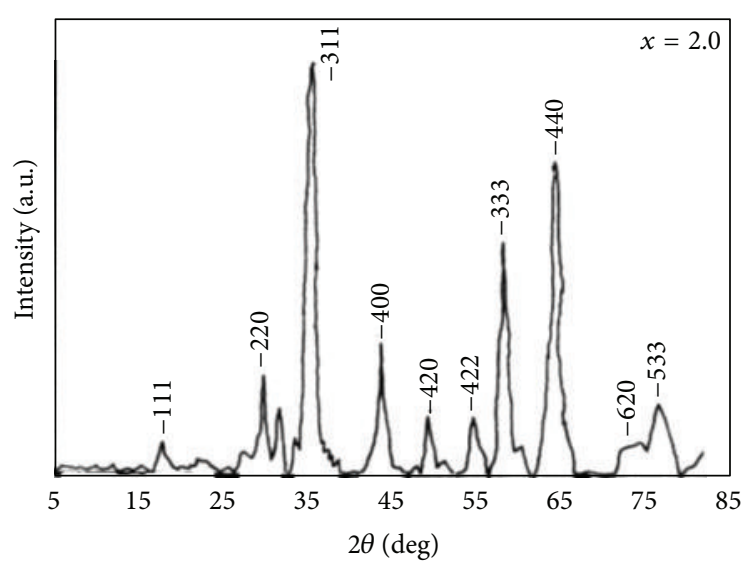

(b)

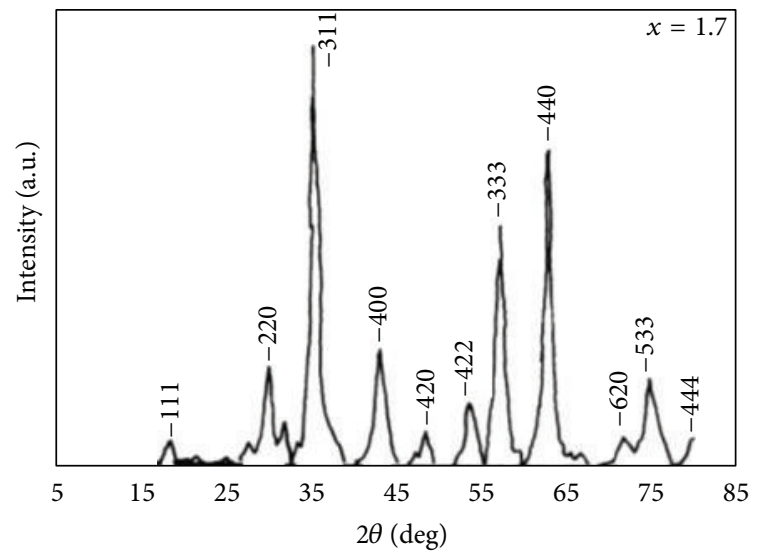

(d)

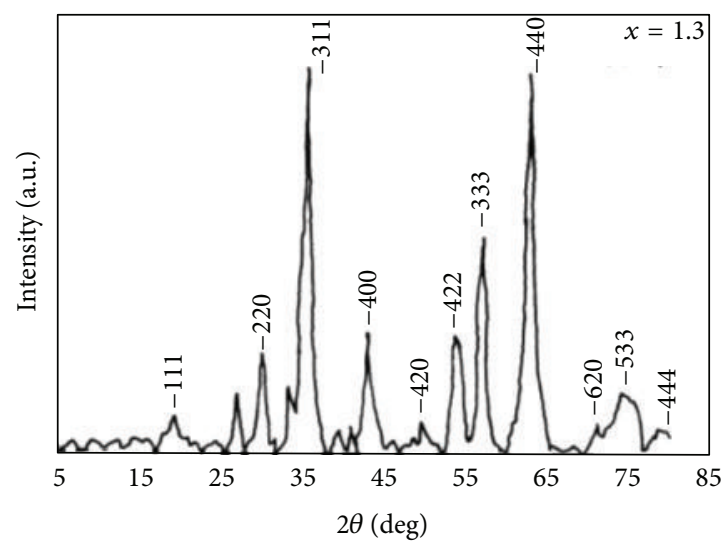

(f)

Figure 3: Typical X-ray diffraction patterns of the $\mathrm{CoCr}_{x} \mathrm{Fe}_{2-x} \mathrm{O}_{4}$ system for different $\mathrm{Cr}^{3+}$ concentration $(x)$.

three-component analysis of the positron lifetime spectra of nanocrystalline materials [24-26], and the intensity $I_{3}$, despite being relatively small $(0.8-1.4 \%)$, indicates the presence of large free volume regions in the intergranular regions of materials when composed by nanometer-sized particles or grains.

3.3. Results of $\mathrm{Cr}^{3+}$ Substitution. Figures 5 and 6 describe the changes occurring in the positron annihilation parameters as a result of $\mathrm{Cr}^{3+}$ substitution for $\mathrm{Fe}^{3+}$ in $\mathrm{CoFe}_{2} \mathrm{O}_{4}$. A close look into the trends of variation helps to identify three distinct stages of defects evolution and/or structural variations. In the first stage spreading over the concentration $x=0.1$ to 0.7 , the two positron lifetimes $\tau_{1}$ and $\tau_{2}$ show remarkable increase in the initial stage and attain saturation. The longer lifetime $\tau_{3}$ and its intensity $I_{3}$ show characteristic decrease that will be discussed later. The second stage of variation is marked for $x>0.7$ till 1.7 during which the lifetimes decrease and the 


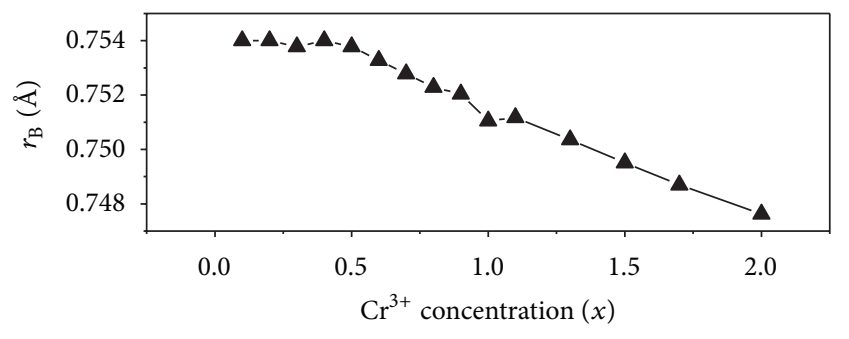

(a)

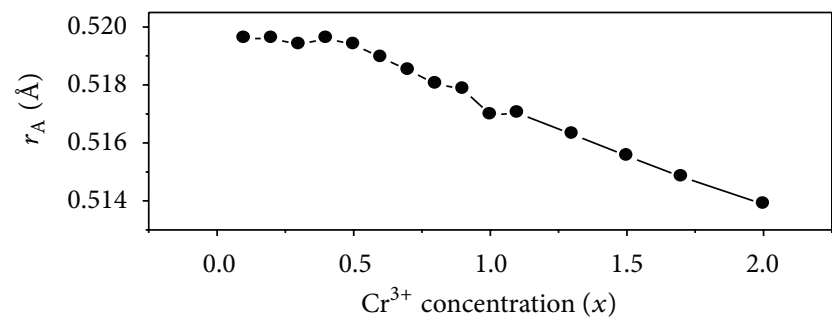

(b)

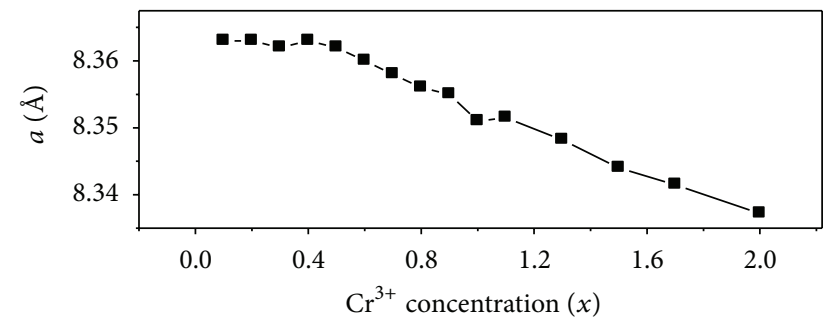

(c)

FIgURE 4: The lattice constant $(a)$ and the radii of the tetrahedral $\left(r_{\mathrm{A}}\right)$ and octahedral $\left(r_{\mathrm{B}}\right)$ sites versus $\mathrm{Cr}^{3+}$ concentration $(x)$.

intensity sharply rises. All these trends are just reversed once again in the last stage from $x=1.8$ to 2.0.

The variation of the different positron annihilation parameters with $\mathrm{Cr}^{3+}$-substitution is thus highly complex in nature, as the potential trapping centers might have changed during the different stages of substitution, due to not only the arrival of a new element but also the relative displacement they may cause in the positioning of the other ions already present in the crystalline structure. Certain information in this direction is available from the results of CDBS measurements shown in Figures 7(a) and 7(b). The data has been analyzed using the usual quotient spectral method in which the projected one-dimensional spectra on the $\left(\left(E_{1}-E_{2}\right) / 2\right)$ axis of the counts in the window $\left(\left(E_{1}+E_{2}\right) / 2\right)=511 \pm 1.2 \mathrm{keV}$ are peak normalized and divided by that of a pure reference sample (Si single crystals) [14,27]. The choice of Si to serve as a reference is not unjustified since it is not a constituent of the material at any stage in this investigation, and the purpose is to magnify the differences in shapes of the momentum distribution curves for easy understanding and interpretation. In Figure 7(a), the ratio curves of the samples with the two extreme compositions, $\mathrm{CoFe}_{2} \mathrm{O}_{4}(x=0.0)$ and $\mathrm{CoCr}_{2} \mathrm{O}_{4}(x=$ 2.0 ), are shown together with the identical curves obtained for the constituent elemental samples. Figure 7(b) illustrates the curves obtained similarly for the $\mathrm{Cr}^{3+}$-substituted samples of a few representative concentrations. The ratio curves of the samples are found having a characteristic peaks at $p_{L}=$ $10.3 \times 10^{-3} m_{0} c$ (where $m_{0}$ is the electron mass and $c$ is the velocity of light). The peaks of the ratio curves of the three constituent metals, that is, $\mathrm{Co}, \mathrm{Fe}$, and $\mathrm{Cr}$, appear at $15.0 \times$ $10^{-3} m_{0} c, 12.2 \times 10^{-3} m_{0} c$, and $11.3 \times 10^{-3} m_{0} c$, respectively, but with decreasing amplitudes. This observation is consistent with the decreasing number of $d$-electrons and decreasing radius of the $3 d$-shell. Thus the peak of the ratio curve of either the pure or any of the $\mathrm{Cr}^{3+}$-substituted samples does not coincide with those of the elemental curves as an ample proof to suggest that positrons are not trapped in oxygen vacancies, a fact even otherwise vindicated by their positive charge that will repel positrons. On the other hand, trapping takes place in the cationic vacancies, and the peak at $p_{L}=10.3 \times 10^{-3} \mathrm{~m}_{0} \mathrm{c}$ common to all the samples and irrespective of the $\mathrm{Cr}^{+}$concentration $(x)$ indicates the encirclement of the defects by oxygen ions. In several of our recent studies on nanocrystalline oxide semiconductors, we have similarly obtained the peak due to annihilation with oxygen electrons at $p_{L}=10.3 \times 10^{-3} \mathrm{~m}_{0} \mathrm{c}[28-30]$.

The identical elemental environment around the positron trapping sites at all concentrations of $\mathrm{Cr}^{3+}$ substitution is further verified from the $S$ versus $W$ plot shown in Figure 8 that is normally used to identify the changes in the predominant type of positron trapping defects at different stages of variation of the experimental parameters. The $S$ and $W$ parameters have been derived from the CDB spectra as the counts falling under segments, respectively, from 0 to $3.75 \times 10^{-3} m_{0} \mathrm{c}$ and from $7.5 \times 10^{-3} \mathrm{~m}_{0} \mathrm{c}$ to $12.25 \times$ $10^{-3} \mathrm{~m}_{0} \mathrm{c}$ normalized by the total counts accumulated under 0 to $37.5 \times 10^{-3} m_{0} c$. The $S$ - $W$ plot is linear, and all the points lie essentially on a straight line. This indicates that positrons essentially encounter similar elemental environments irrespective of the cationic redistribution. This is a further credence to the argument that the defects which trap positrons are surrounded by oxygen ions, and therefore, the traps are none other than the cationic vacancies. But there are variations in the intensity of annihilation with the oxygen electrons, as indicated by the individual variations of the $S$ and $W$ parameters with $\mathrm{Cr}^{3+}$ concentration $(x)$ shown in Figures 9(a) and 9(b). (For the sake of clarity, the curves of not all the samples are shown in Figure 7(a) or Figure 7(b), but the peak coordinates of all the curves are shown in Figure 8). From Figures 9(a) and 9(b) also, we can distinguish from one another basically three regions, the demarcation being identical to that mentioned in the case of the positron lifetime results. The first two regions $(x=0.0-0.7$ and $x=$ $0.7-1.7$ ) are characterized by a fall and a rise of the peaks of the curves, and the last stage is marked by again a fall. It can be argued that although the annihilation environment of positrons essentially remains identical, they are trapped at different stages of $\mathrm{Cr}^{3+}$ substitution by the defects situated at different sites in the lattice structure. These points are further discussed in detail afterwards.

The insensitivity of the CDB spectra to the oxygen vacancies can be explained on the basis of the results of positron lifetime measurements as well. The difference between the 
lifetime characteristic of defects (i.e., $\tau_{2}$ ) and the bulk lifetime $\tau_{f}$ is normally considered as an indication of the size of the defect. The enhancement in the positron lifetime due to trapping in monovacancies is $\sim 40-80$ ps in typical metals and alloys [31]. Assuming that $\tau_{2}=356 \mathrm{ps}$ is an upper limit of the positron lifetime in vacancy clusters in the unsubstituted sample, $\tau_{2}-\tau_{f}=356-199=157$ ps will correspond to defects much larger than monovacancies. Theoretical estimations in Fe, which is normally bcc in structure but a constituent of the present samples, have shown the enhancement of positron lifetime in a neutral vacancy cluster composed of 4-5 neighboring monovacancies as 152 ps [32]. Considering these facts, the positron trapping site in the undoped alloy can be conceived to be a vacancy cluster composed of the monovacancy created by the absence of a doubly ionized cation and four of its coordinated oxygen ions. Based on Xray diffraction, magnetization and Mossbauer results, Mohan et al. [10] have shown that the $\mathrm{CoFe}_{2} \mathrm{O}_{4}(x=0.0)$ is a nearly complete inverse spinel and the ionic distribution in it is of the form $\left(\mathrm{Fe}^{3+}{ }_{0.9} \mathrm{Co}^{2+}{ }_{0.1}\right)^{\mathrm{A}}\left[\mathrm{Co}^{2+}{ }_{0.9} \mathrm{Fe}^{3+}{ }_{1.1}\right]^{\mathrm{B}} \mathrm{O}_{4}{ }^{2-}$. The absence of a $\mathrm{Co}^{2+}$ ion with four oxygen neighbor ions will give rise to a neutral pentavacancy cluster in which positrons can be trapped and annihilated. The other possibility of the absence of a trivalent cation with four neighboring oxygen ions cannot be ruled out as it would have enhanced positron trapping due to surplus negative charge, and hence, it is necessary to point out whether the said vacancy cluster is centered at the (A-) site or at the (B-) site. This can be answered by looking at the effects of $\mathrm{Cr}^{3+}$ substitution on the cationic redistribution. A schematic diagram showing the two neighboring octants of a normal spinel structure is shown in Figure 10. At the very onset of substitution, a drastic drop in the intensity of the peak in the CDB spectra (represented by the $W$ parameter) is observed (Figures 7 (b) and 9(b)), and it indicates the diminishing positron annihilation probability with oxygen electrons. The ionic distributions obtained from the X-ray diffraction peak intensity analysis for samples with the different concentrations of the $\mathrm{Cr}^{3+}$ ions are given in Table 1. Thus, for example, the distribution is $\left(\mathrm{Fe}^{3+}{ }_{0.8} \mathrm{Co}^{2+}{ }_{0.2}\right){ }^{\mathrm{A}}\left[\mathrm{Co}^{2+}{ }_{0.8} \mathrm{Cr}^{3+}{ }_{0.1} \mathrm{Fe}^{3+}{ }_{1.1}\right]^{\mathrm{B}} \mathrm{O}_{4}{ }^{2-}$ for $x=0.1$. This implies that the substituted $\mathrm{Cr}^{3+}$ ions initially replace an equal number of $\mathrm{Fe}^{3+}$ ions from the (B-) sites, but simultaneously an equal number of $\mathrm{Fe}^{3+}$ ions from the (A) sites move over to the (B-) sites in exchange of $\mathrm{Co}^{2+}$ ions from the (B-) sites to the (A-) sites. In effect, an inversion of the spinel structure is prompted as a result of the substitution process. Hence, as shown in Table 1, the number of $\mathrm{Fe}^{3+}$ ions at the (A-) sites decreases whereas that at the (B-) sites remains unaltered till $x=0.7$ compositions. Since CDB spectra indicate diminishing annihilation with oxygen electrons and the positron lifetime $\tau_{2}$ increases from 356 ps to $374 \mathrm{ps}$, it is reasonable to argue that the defects in the sample with $x=0.1$ are larger in size and increasingly deficient in oxygen ions than those in the unsubstituted $(x=0.0)$ sample. In other words, the defects were centered at the (A-) sites in the unsubstituted sample and at the (B-) sites in the substituted samples. We attribute the second positron lifetime component $\tau_{2}$ to such large vacancy clusters.
As already stated, the substitution or doping resulted in sharp rises in the two lifetimes, $\tau_{1}$ and $\tau_{2}$. The intensity $I_{2}$, however, did not show any change. It is, therefore, a local effect in which the vacancy cluster has undergone an increase in size. From EDAX studies, we have estimated the actual concentration of the $\mathrm{Cr}^{3+}$ ions effectively substituted in the crystallites (Figure 1). It has been found that the (B-) sites suffered from nonstoichiometric deficiencies of $\mathrm{Cr}^{3+}$ ions, and hence, the $\mathrm{Co}^{2+}$ ions transferred to the (A-) sites are also less in number than that predicted by the formula $\left(\mathrm{Fe}^{3+}{ }_{0.9-x} \mathrm{Co}^{2+}{ }_{0.1+x}\right)^{\mathrm{A}}\left[\mathrm{Co}_{0.9-x}{ }^{2+} \mathrm{Cr}^{3+}{ }_{x} \mathrm{Fe}^{3+}{ }_{1.1}\right]^{\mathrm{B}} \mathrm{O}_{4}{ }^{2-}$. The result is that the vacancies so created will add to the existing vacancy clusters, resulting in further increase in their size and thereby enhancing the positron lifetimes. However, the deficiency decreases on subsequent doping, and therefore, the lifetime $\tau_{2}$ and intensity $I_{2}$ remain rather unchanged in the range of concentration from 0.1 to 0.7 .

On the other hand, the concentration of $\mathrm{Fe}^{3+}$ ions at the (B-) sites does not change despite the substitution by $\mathrm{Cr}^{3+}$ ions till $x=0.7$ due to the simultaneous inversion process in which the $\mathrm{Co}^{2+}$ ions migrate to the (A-) sites [10]. This means that, the $\mathrm{Cr}^{3+}$ ions occupy the (B-) sites. The $\mathrm{Cr}^{3+}$ substitution $(x)$ above this value does not indicate further inversion, and hence, the effective number of $\mathrm{Fe}^{3+}$ ions at the (B-) sites starts decreasing (Table 1), whereas at $x=0.7$ the peak in the $\mathrm{CDB}$ spectrum appears the sharpest, and the positron lifetimes start decreasing above this concentration, indicating a reduction in the size of the vacancy clusters. The intensity $I_{2}$ increases (Figure 5). The fact that positrons are now annihilating at sites which are smaller in size can be understood as follows. The lattice constant of the $\mathrm{CoCr}_{x} \mathrm{Fe}_{2-x} \mathrm{O}_{4}$ samples steeply reduces in samples with increased $\mathrm{Cr}^{3+}$ concentration (Figure 4). The contraction of the lattice can be attributed to the slightly smaller ionic radius of $\mathrm{Cr}^{3+}(0.630 \AA)$ compared to that of $\mathrm{Fe}^{3+}(0.640 \AA)$. Using the experimentally found values of the lattice constant $(a)$ and the oxygen positional parameter $(u)$ [1], it is possible to calculate the radii of the tetrahedral and octahedral sites, $r_{\mathrm{A}}$ and $r_{\mathrm{B}}$, respectively, using the relations [1]

$$
\begin{gathered}
r_{\mathrm{A}}=\sqrt{3}\left(u-\frac{1}{4}\right) a-R_{0}, \\
r_{\mathrm{B}}=\left(\frac{5}{8}-u\right) a-R_{0} .
\end{gathered}
$$

Here, $R_{0}$ is the radius of the oxygen ion (taken as $1.32 \AA$ ), and $u$ is taken as $=0.379$ considering that $\mathrm{CoCr}_{x} \mathrm{Fe}_{2-x} \mathrm{O}_{4}$ is fully inverse at $x=0.0$ composition $[1,2]$. The site radii for the different compositions estimated from the above equations are also shown in Figure 4. Increasing the concentration of $\mathrm{Cr}^{3+}$ will result in filling the vacancies at the octahedral sites, and, owing to the positive charge, positrons are trapped in a reducing number in the $\mathrm{Cr}^{3+}$-vacancy complexes so formed. On the other hand, while the octahedral sites were large enough to accommodate the $\mathrm{Co}^{2+}$ ions, the radii of the tetrahedral sites are magnitude-wise smaller than its ionic radius $(0.740 \AA)$, and hence, it is likely that a fraction of 


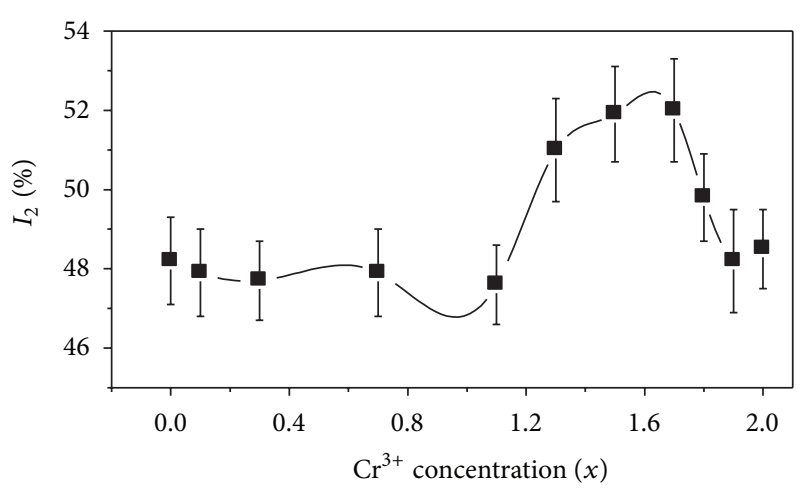

(a)

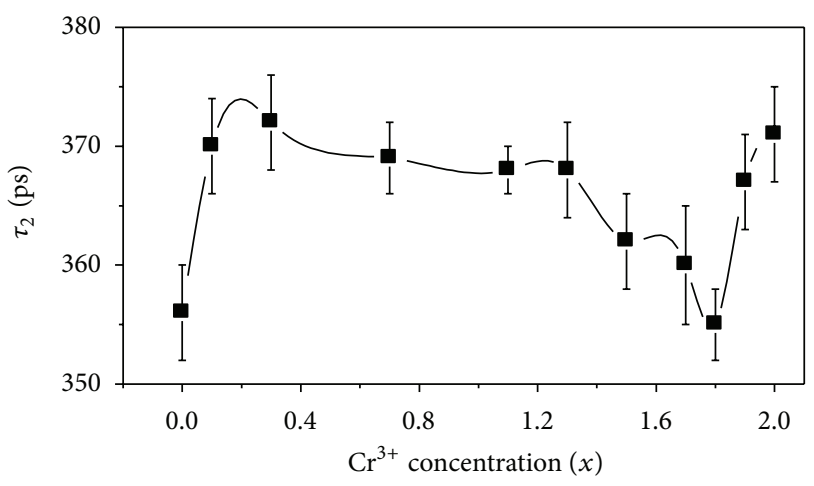

(b)

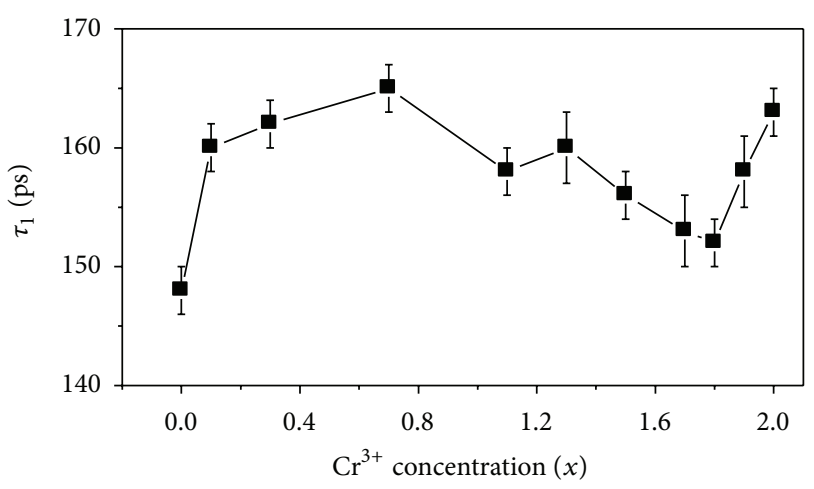

(c)

FIGURE 5: The positron lifetimes, $\tau_{1}$ and $\tau_{2}$, and intensity $I_{2}$ versus $\mathrm{Cr}^{3+}$ concentration $(x)$.

the tetrahedral sites are unoccupied during the inversion of the spinel structure at concentrations $x<0.7$. As a result, positrons now that are no more trapped at the octahedral vacancies will move over to the vacancies at the tetrahedral sites and get trapped there. The fast decreasing positron lifetimes support this argument since the tetrahedral vacancy clusters are smaller than the octahedral ones. The availability of additional trapping sites expectedly increases the intensity $I_{2}$ as well. Considering that positrons are now getting trapped in the vacancy clusters present at the tetrahedral sites, the lattice contraction would directly influence their lifetime, and the observations in the range mentioned above are in accordance with the same. A careful study of the ionic

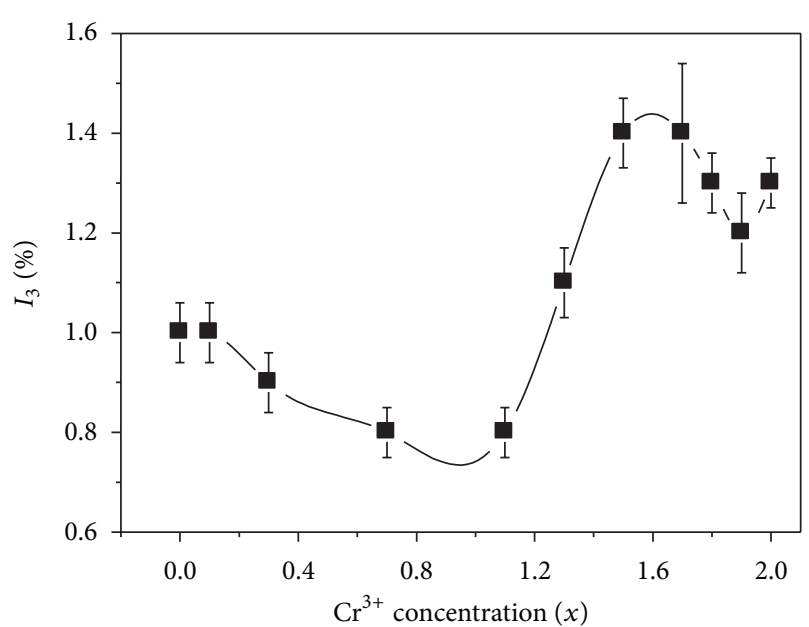

(a)

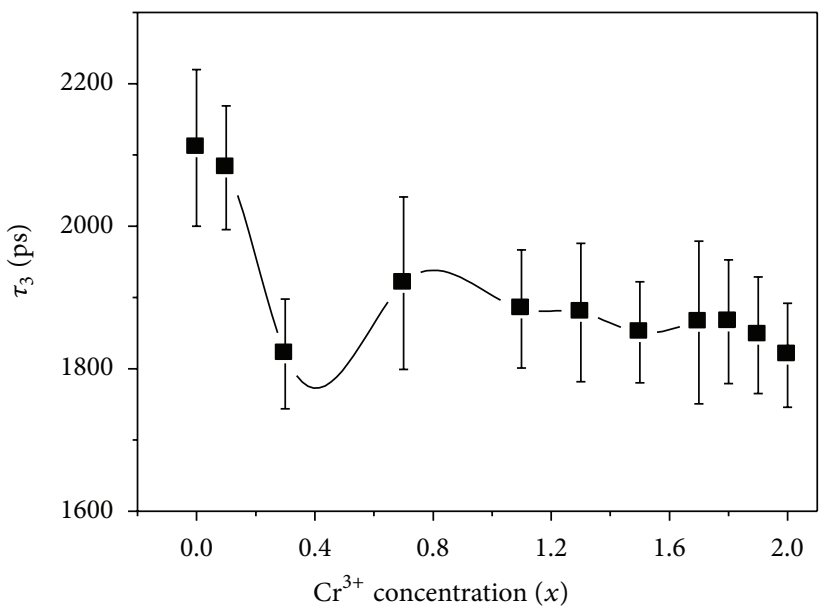

(b)

FIGURE 6: The orthopositronium lifetime $\tau_{3}$ and intensity $I_{3}$ versus $\mathrm{Cr}^{3+}$ content $(x)$.

distribution shown in Table 1 makes us realize that from $x=0.7$ onwards till $x=1.7$, the occupancies of $\mathrm{Fe}^{3+}$ and $\mathrm{Co}^{2+}$ at the (A-) sites remain unchanged, whereas the $\mathrm{Cr}^{3+}$ ions directly replace the $\mathrm{Fe}^{3+}$ ions at the (B-) sites. At $x=1.7$, all the $\mathrm{Fe}^{3+}$ ions at the (B-) sites are replaced by $\mathrm{Cr}^{3+}$ ions (Table 1).

The last stage in the variation of the positron annihilation parameters versus the $\mathrm{Cr}^{3+}$ concentration $(x)$ is observed between $x=1.8$ and 2.0. During $x=0.7$ to 1.7, the cation distribution at the (A-) sites remained unaltered as $\mathrm{Fe}^{3+}{ }_{0.3} \mathrm{Co}^{2+}{ }_{0.7}$, while $\mathrm{Cr}^{3+}$ ions monotonically replaced the $\mathrm{Fe}^{3+}$ ions at the (B-) sites with the $\mathrm{Co}^{2+}$ concentration at the (B-) sites remaining unaltered as 0.3. As the lattice contraction continues, the transformation of the spinel structure from the inverse to the normal configuration that had started during $x=0.1-0.7$ and discontinued during $x=0.7-$ 1.7 gets completed. From octahedral site stabilization energy considerations, it is known that cobaltchromite $\left(\mathrm{CoCr}_{2} \mathrm{O}_{4}\right)$ is a normal spinel [10]. In earlier positron annihilation studies 


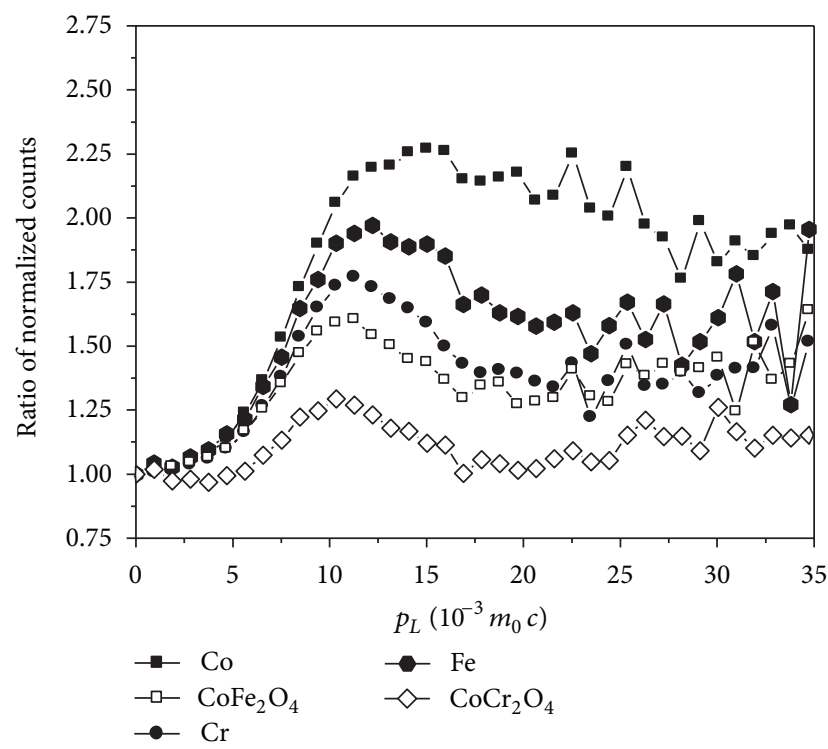

(a)

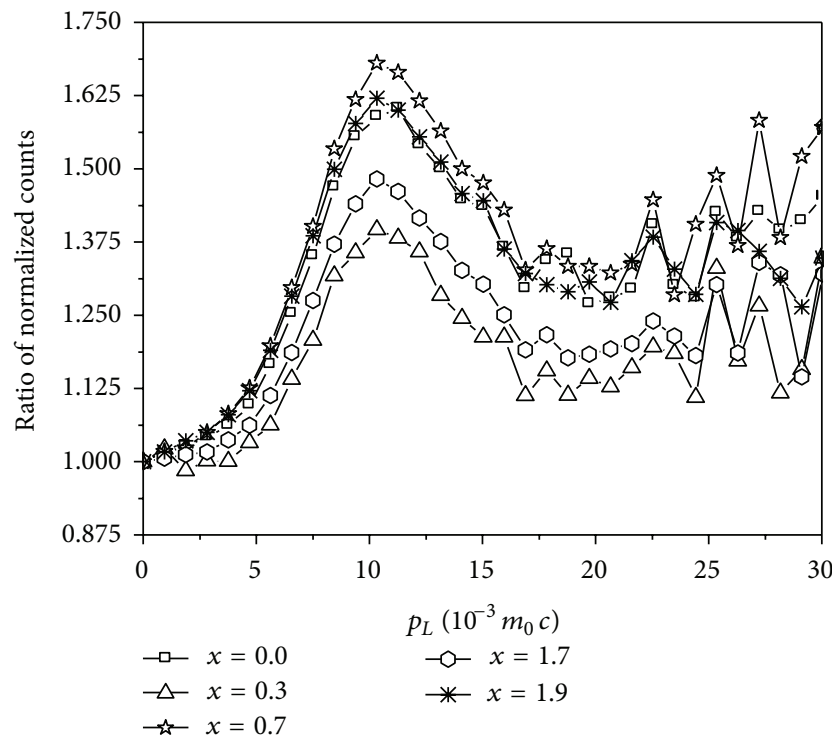

(b)

Figure 7: The ratio curves generated from the coincidence Doppler broadening spectra of the different samples-(a) elements $\mathrm{Co}, \mathrm{Fe}$, and $\mathrm{Cr}$ besides $\mathrm{CoCr}_{x} \mathrm{Fe}_{2-x} \mathrm{O}_{4}$ of $x=0.0$ and 2.0; (b) $\mathrm{CoCr}_{x} \mathrm{Fe}_{2-x} \mathrm{O}_{4}$ of $x=0.0,0.3,0.7,1.7$, and 1.9. All the spectra had been peak normalized and then divided by that of a pure reference Si sample in order to generate the ratio curves.

of nanocrystalline $\mathrm{ZnFe}_{2} \mathrm{O}_{4}$ [24] and $\mathrm{NiFe}_{2} \mathrm{O}_{4}[25,33]$, the positron lifetimes had been observed to decrease when a normal spinel ferrite transforms to an inverse spinel, and conversely they increase when the transformation is just the opposite. These observations had been verified through Mossbauer spectroscopic studies too $[25,33]$. Since the two positron lifetimes, $\tau_{1}$ and $\tau_{2}$, drastically increase during

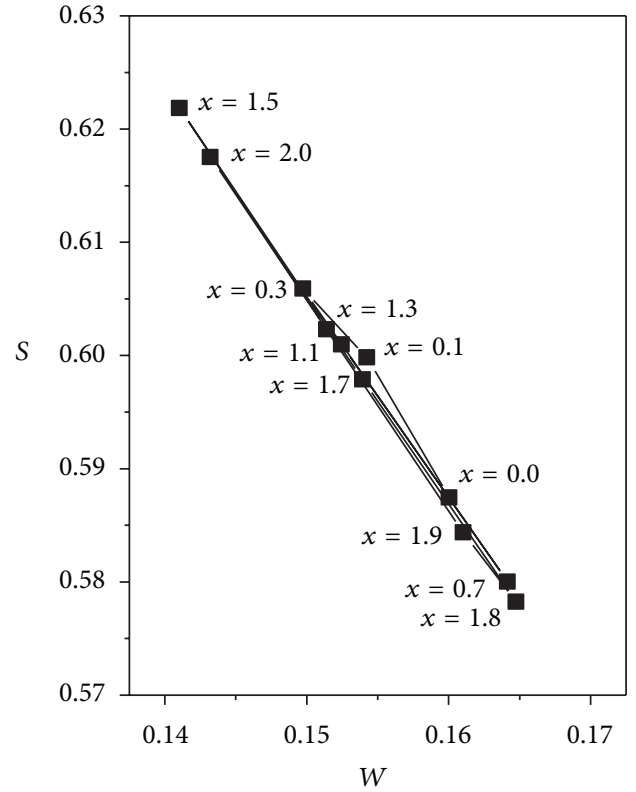

Figure 8: The $S$ - $W$ plot of the $\mathrm{Cr}^{3+}$-substituted samples.

$x=1.8$ and 2.0 (Figure 5), this stage is attributed to the total transformation of the partly inverse $\mathrm{CoCr}_{x} \mathrm{Fe}_{2-x} \mathrm{O}_{4}$ to the fully normal $\mathrm{CoCr}_{2} \mathrm{O}_{4}$. Note further that unlike during $x=0.1-0.7$ when the intensity $I_{2}$ did not show any change, it decreases in the final stage of inversion indicating the full occupancy of the (A-) sites by $\mathrm{Co}^{2+}$ ions. The fact remains that the spinel structures normally suffer from nonstoichiometric disorders, and therefore, vacancy clusters are inherently inbuilt in the structure. The large value of $\tau_{2}$ with still an appreciable intensity $I_{2}$ supports this argument.

As has been already pointed out, the longest lifetime $\tau_{3}$ and its intensity $I_{3}$ are due to the nanocrystalline dimensions of the samples, and they result from positronium atoms annihilating at the intergranular region. Hence, they need not necessarily reflect the effects of any change in the vacancy cluster dynamics within the grains. Yet $\tau_{3}$ shows a sudden decrease during the initial stage $x=0.1$ to 0.7 and then remains constant (Figure 6). The intensity $I_{3}$ gradually falls during this stage but shows a characteristic rise during the second stage $x=0.7$ to 1.7 and then remains constant (Figure 6). The initial fall can be attributed to small traces of $\mathrm{Cr}^{3+}$ ions, unsuccessful in being incorporated into the spinel structure and hence left to remain in trace amounts within the intergranular region. EDAX analysis also indicated frustration even within the lattice due to the failure in the complete substitution of $\mathrm{Fe}^{3+}$ by the $\mathrm{Cr}^{3+}$ ions in the system. In the latter stage (i.e., $x>0.7$ ), the lattice contraction has expectedly resulted in a decrease by $0.3 \%$ in the grain size, and thereby, the number of positrons reaching out on the grain surfaces has slightly increased.

Although it is known that the magnetic properties of the samples undergo rapid and interesting changes during the $\mathrm{Cr}^{3+}$ substitution, correlating such changes to the behavior of positron annihilation parameters is never straightforward 


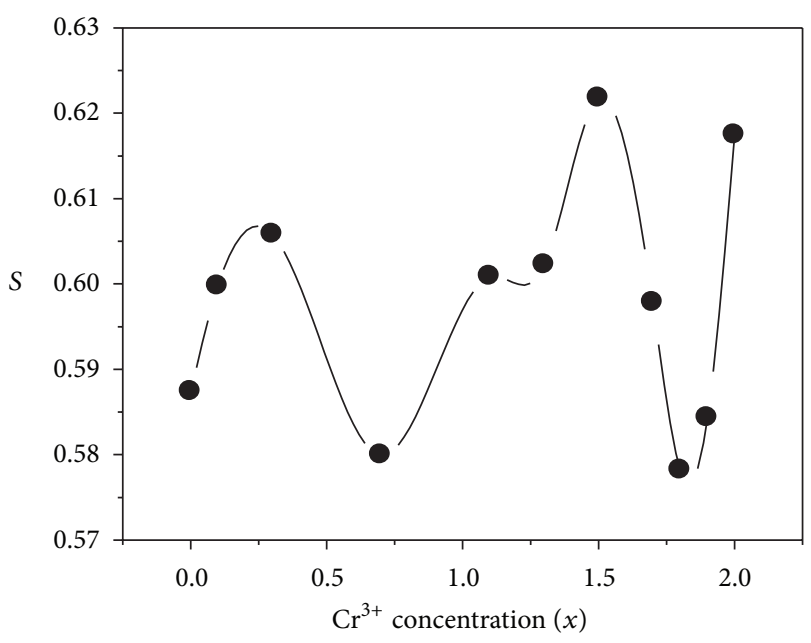

(a)

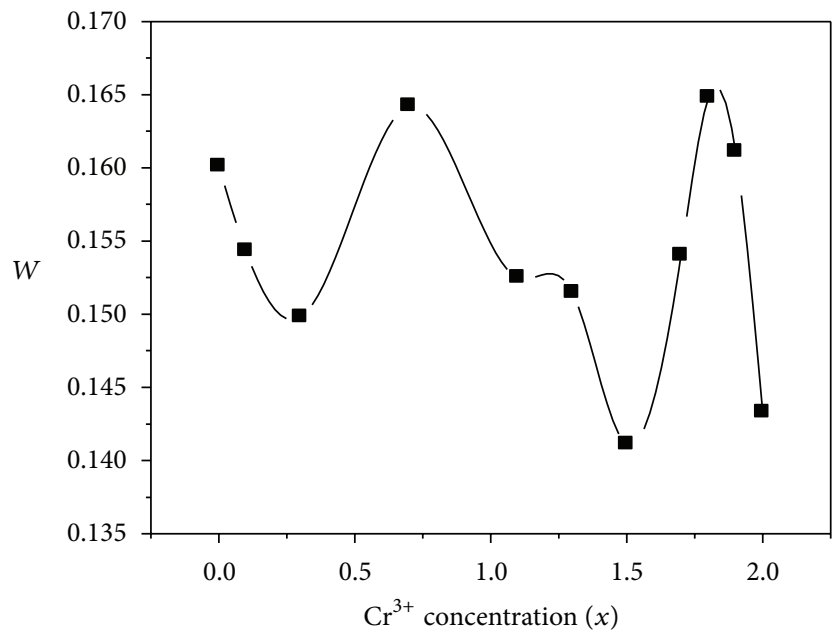

(b)

Figure 9: The $S$ and $W$ parameters versus $\mathrm{Cr}^{3+}$ concentration $(x)$.

and is not attempted here. The structural properties and their changes, as depicted by the positron annihilation parameters and their variations, may influence the magnetic properties, which need to be investigated by appropriate experimental methods.

\section{Conclusions}

In understanding the effects of $\mathrm{Cr}^{3+}$-substitution in place of $\mathrm{Fe}^{3+}$ in $\mathrm{CoFe}_{2} \mathrm{O}_{4}$ studied by positron annihilation spectroscopy, we have offered the physical interpretation of the results in terms of three distinct stages of defect evolution and interaction. First, the unsubstituted ferrite $\left(\mathrm{CoFe}_{2} \mathrm{O}_{4}\right.$, $x=0.0)$ itself was found to contain large vacancy clusters. These clusters are identified as being present at the (A-) sites with the divalent $\mathrm{Co}^{2+}$ ion and four of its coordinated oxygen ions making way for such very strong trapping centers for positrons. At the onset of $\mathrm{Cr}^{3+}$-substitution $(x)$, the positron lifetimes increased due to the transfer of positron trapping

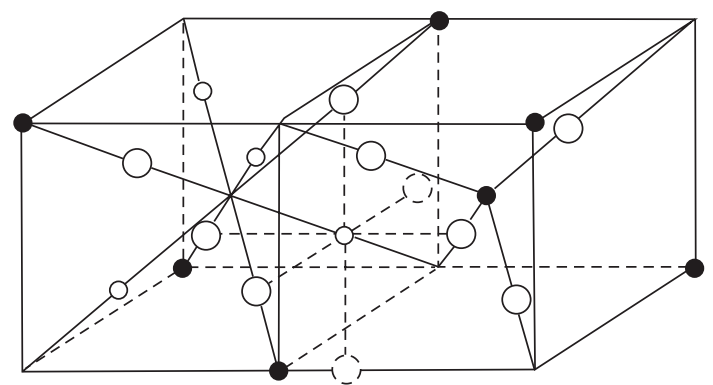

FIGURE 10: Schematic representation of the two neighboring octants of a normal spinel structure. The large circles represent oxygen ions. The small solid and open circles represent the cations at the tetrahedral and octahedral sites, respectively, as illustrated in [33].

into defects to the (B-) sites. In the second stage from $x=$ 0.7 to $x=1.7$, a concomitant lattice contraction influenced the positron annihilation characteristics. This contraction is attributed to the slightly smaller ionic radius of $\mathrm{Cr}^{3+}$ than that of $\mathrm{Fe}^{3+}$. There is also a change in the positron trapping sites from the vacancy clusters at the (B-) sites back to those at the (A-) sites. The last stage is marked by a full inversion of the structure to that of a normal spinel chromite, and the positron annihilation parameters depicted this stage with a characteristic reversal of the trend of variation with the $\mathrm{Cr}^{3+}$ concentration.

Finally, we conclude that the positron lifetime measurements complemented by results from coincidence Doppler broadening spectroscopy can be a viable alternative experimental tool to monitor the generation and evolution of structural disorders in $\mathrm{XY}_{2} \mathrm{O}_{4}$ (where $\mathrm{X}$ and $\mathrm{Y}$ are divalent and trivalent metals, resp.) systems during physical treatments like doping and grain size reduction. Positron annihilation parameters are seen to sense, directly or indirectly, physical phenomena of different kinds and implications like the redistribution of cations, lattice contraction or expansion, and structural transformations in certain cases [24-26].

\section{Acknowledgments}

The authors are grateful to Professor, Indranil Das of Saha Institute of Nuclear Physics (SINP), Kolkata, for providing the reference $\mathrm{Co}$ and $\mathrm{Cr}$ samples for CDBS experiments. Some useful discussions with Dr. N. N. Mondal and a graphical illustration (Figure 10) prepared by Mr. Pradipta K. Das are also gratefully acknowledged. One of the authors (Kunal B. Modi) is thankful to Professor H. H. Joshi for providing some of the ferrite samples.

\section{References}

[1] J. Smit and H. P. J. Wijn, Ferrites-Physical Properties of Ferromagnetic Oxides in Relation to Their Technical Applications, N. V. Philips Gloeilampenfabrieken, Eindhoven, The Netherlands, 1959.

[2] F. Scordari, Fundamentals of Crystallography, edited by C. Giacovazzo, Oxford University Press, New York, NY, USA, 1992. 
[3] W. B. Cross, L. Affleck, M. V. Kuznetsov, and I. P. Parkin, "Selfpropagating high-temperature synthesis of ferrites $\mathrm{MFe}_{2} \mathrm{O} 4$ $(\mathrm{M}=\mathrm{Mg}, \mathrm{Ba}, \mathrm{Co}, \mathrm{Ni}, \mathrm{Cu}, \mathrm{Zn})$; reactions in an external magnetic field," Journal of Materials Chemistry, vol. 9, no. 10, p. 2545, 1999.

[4] K. Tomiyasu, J. Fukunaga, and H. Suzuki, "Magnetic shortrange order and reentrant-spin-glass-like behavior in $\mathrm{CoCr}_{2} \mathrm{O}_{4}$ and $\mathrm{MnCr}_{2} \mathrm{O}_{4}$ by means of neutron scattering and magnetization measurements," Physical Review B, vol. 70, no. 21, Article ID 214434, 12 pages, 2004.

[5] V. T. Thanki, N. N. Jani, U. V. Chhaya, H. H. Joshi, and R. G. Kulkarni, "Magnetic properties of $\mathrm{CoFe}_{2-x} \mathrm{Cr}_{x} \mathrm{O}_{4}$ synthesized by co-precipitation method," AsianJournal of Physics, vol. 6, no. 1-2, p. 222, 1997.

[6] G. A. Sawatzky, F. van der Woude, and A. H. Morrish, "Cation distributions in octahedral and tetrahedral sites of the ferrimagnetic spinel $\mathrm{CoFe}_{2} \mathrm{O}_{4}$," Journal of Applied Physics, vol. 39, no. 2, pp. 1204-1205, 1968.

[7] G. Lawes, B. Melot, K. Page et al., "Dielectric anomalies and spiral magnetic order in $\mathrm{CoCr}_{2} \mathrm{O}_{4}$," Physical Review B, vol. 74, no. 2, Article ID 024413, 6 pages, 2006.

[8] N. Menyuk, K. Dwight, and A. Wold, "Ferrimagnetic spiral configurations in cobalt chromite," Journal de Physique, vol. 25, pp. 528-536, 1964.

[9] A. Hauet, J. Teillet, B. Hannoyer, and M. Lenglet, "Mössbauer study of Co and Ni ferrichromites," Physica Status Solidi (A), vol. 103, no. 1, pp. 257-261, 1987.

[10] H. Mohan, I. A. Shaikh, and R. G. Kulkarni, "Magnetic properties of the mixed spinel $\mathrm{CoFe}_{2-x} \mathrm{CrxO}_{4}$," Physica $B$, vol. 217, no. 3-4, pp. 292-298, 1996.

[11] B. G. Tolesha, S. E. Shrisath, M. L. Mane, S. M. Patange, S. S. Jadhav, and K. M. Jadhav, "Autocombustion high-temperature synthesis, structural, and magnetic properties of $\mathrm{CoCr}_{x} \mathrm{Fe}_{2-x} \mathrm{O}_{4}$ $(0 \leq x \leq 1.0)$," The Journal of Physical Chemistry C, vol. 115, no. 43, pp. 20905-20912, 2011.

[12] R. W. Siegel, "Positron annihilation spectroscopy," Annual Review of Materials Science, vol. 10, pp. 393-425, 1980.

[13] S. Biswas, S. Kar, S. Chaudhuri, and P. M. G. Nambissan, " $\mathrm{Mn}^{2+}$ induced substitutional structural changes in $\mathrm{ZnS}$ nanoparticles as observed from positron annihilation studies," Journal of Physics: Condensed Matter, vol. 20, no. 23, Article ID 235226, 2008.

[14] P. Asoka-Kumar, M. Alatalo, V. J. Ghosh, A. C. Kruseman, B. Nielsen, and K. G. Lynn, "Increased elemental specificity of positron annihilation spectra," Physical Review Letters, vol. 77, no. 10, pp. 2097-2100, 1996.

[15] B. D. Cullity, Elements of X-Ray Diffraction, Addison-Wesley, Reading, Mass, USA, 1978.

[16] C. Dong, "PowderX: windows-95-based program for powder Xray diffraction data processing," Journal of Applied Crystallography, vol. 32, p. 838, 1999.

[17] M. J. Buerger, Crystal Structure Analysis, Wiley, New York, NY, USA, 1960.

[18] H. Ohnish and T. Teranishi, "Crystal distortion in copper ferrite-chromite series," Journal of the Physical Society of Japan, vol. 16, pp. 35-43, 1961.

[19] V. T. Thanki, "Study on magnetic properties of oxide materials," [Ph.D. thesis], Saurashtra University, Rajkot, India, 1996, (unpublished).

[20] J. V. Olsen, P. Kirkegaard, N. J. Pedersen, and M. Eldrup, "PALSfit: a new program for the evaluation of positron lifetime spectra," Physica Status Solidi (C), vol. 4, no. 10, pp. 4004-4006, 2007.
[21] T. Koida, S. F. Chichibu, A. Uedono et al., "Correlation between the photoluminescence lifetime and defect density in bulk and epitaxial ZnO," Applied Physics Letters, vol. 82, no. 4, p. 532, 2003.

[22] A. Zubiaga, F. Tuomisto, F. Plazaola et al., "Zinc vacancies in the heteroepitaxy of $\mathrm{ZnO}$ on sapphire: influence of the substrate orientation and layer thickness," Applied Physics Letters, vol. 86, no. 4, Article ID 042103, 3 pages, 2005.

[23] P. Hautojarvi and C. Corbel, "For a detailed discussion on different cases of positron trapping in solids," in Positron Spectroscopy of Solids, pp. 491-532, IOS Press, Amsterdam, The Netherlands, 1995.

[24] P. M. G. Nambissan, C. Upadhyay, and H. C. Verma, "Positron lifetime spectroscopic studies of nanocrystalline $\mathrm{ZnFe}_{2} \mathrm{O}_{4}$," Journal of Applied Physics, vol. 93, no. 10, pp. 6320-6326, 2003.

[25] S. Chakraverty, S. Mitra, K. Mandal, P. M. G. Nambissan, and S. Chattopadhyay, "Positron annihiliation studies of some anomalous features of $\mathrm{NiFe}_{2} \mathrm{O}_{4}$ nanocrystals grown in $\mathrm{SiO}_{2}$," Physical Review B, vol. 71, Article ID 024115, 8 pages, 2005.

[26] S. Chakrabarti, S. Chaudhuri, and P. M. G. Nambissan, "Positron annihilation lifetime changes across the structural phase transition in nanocrystalline $\mathrm{Fe}_{2} \mathrm{O}_{3}$," Physical Review $B$, vol. 71, no. 6, Article ID 064105, 6 pages, 2005.

[27] Y. Nagai, T. Nonaka, M. Hasegawa et al., "Direct evidence of positron trapping at polar groups in a polymer-blend system," Physical Review B, vol. 60, no. 17, pp. 11863-11866, 1999.

[28] T. Ghoshal, S. Biswas, S. Kar, S. Chaudhuri, and P. M. G. Nambissan, "Positron annihilation spectroscopic studies of solvothermally synthesized $\mathrm{ZnO}$ nanobipyramids and nanoparticles," Journal of Chemical Physics, vol. 128, no. 7, Article ID 074702, 2008, Virtual Journal of Nanoscale Science and Technology, vol. 17, no. 8, 2008.

[29] T. Ghoshal, S. Kar, S. Biswas, S. K. De, and P. M. G. Nambissan, "Vacancy-type defects and their evolution under Mn substitution in single crystalline $\mathrm{ZnO}$ nanocones studied by positron annihilation," Journal of Physical Chemistry C, vol. 113, no. 9, pp. 3419-3425, 2009.

[30] B. Roy, B. Karmakar, P. M. G. Nambissan, and M. Pal, "Mn substitution effects and associated defects in $\mathrm{ZnO}$ nanoparticles studied by positron annihilation," Nano, vol. 6, no. 2, p. 173, 2011.

[31] I. K. MacKenzie, Positron Solid State Physics, edited by W. Brandt and A. Dupasquier, North Holland, Amsterdam, The Netherlands, 1983.

[32] M. J. Puska and R. M. Nieminen, "Defect spectroscopy with positrons: a general calculational method," Journal of Physics F, vol. 13, no. 2, pp. 333-346, 1983.

[33] S. Mitra, K. Mandal, S. Sinha, P. M. G. Nambissan, and S. Kumar, "Size and temperature dependent cationic redistribution in $\mathrm{NiFe}_{2} \mathrm{O}_{4}\left(\mathrm{SiO}_{2}\right)$ nanocomposites: positron annihilation and Mössbauer studies," Journal of Physics D, vol. 39, no. 19, pp. 4228-4235, 2006. 

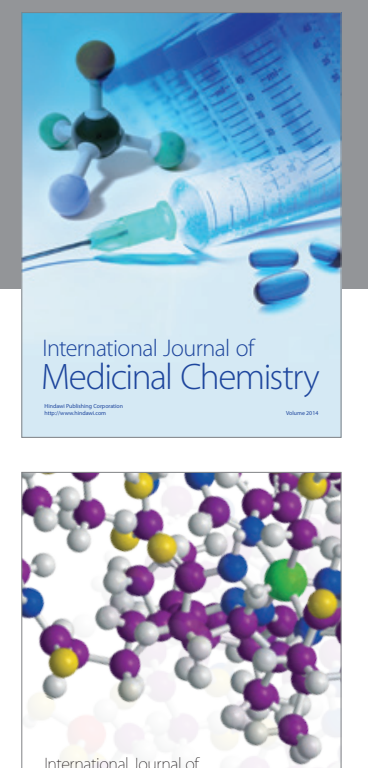

\section{Carbohydrate} Chemistry

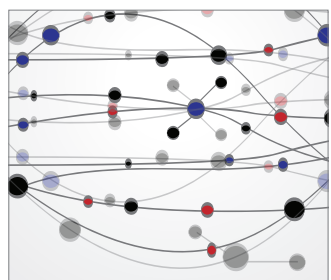

The Scientific World Journal
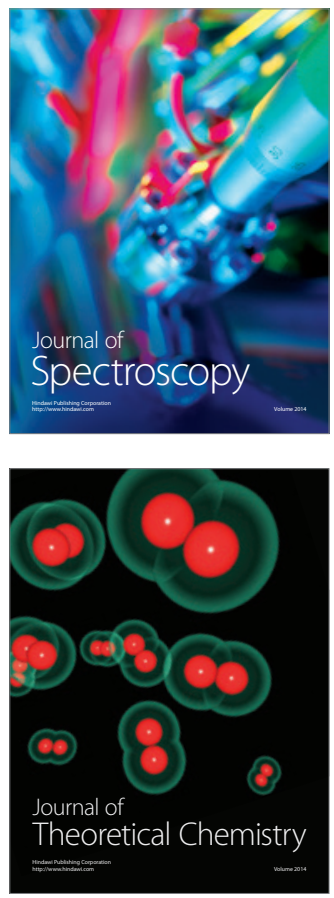
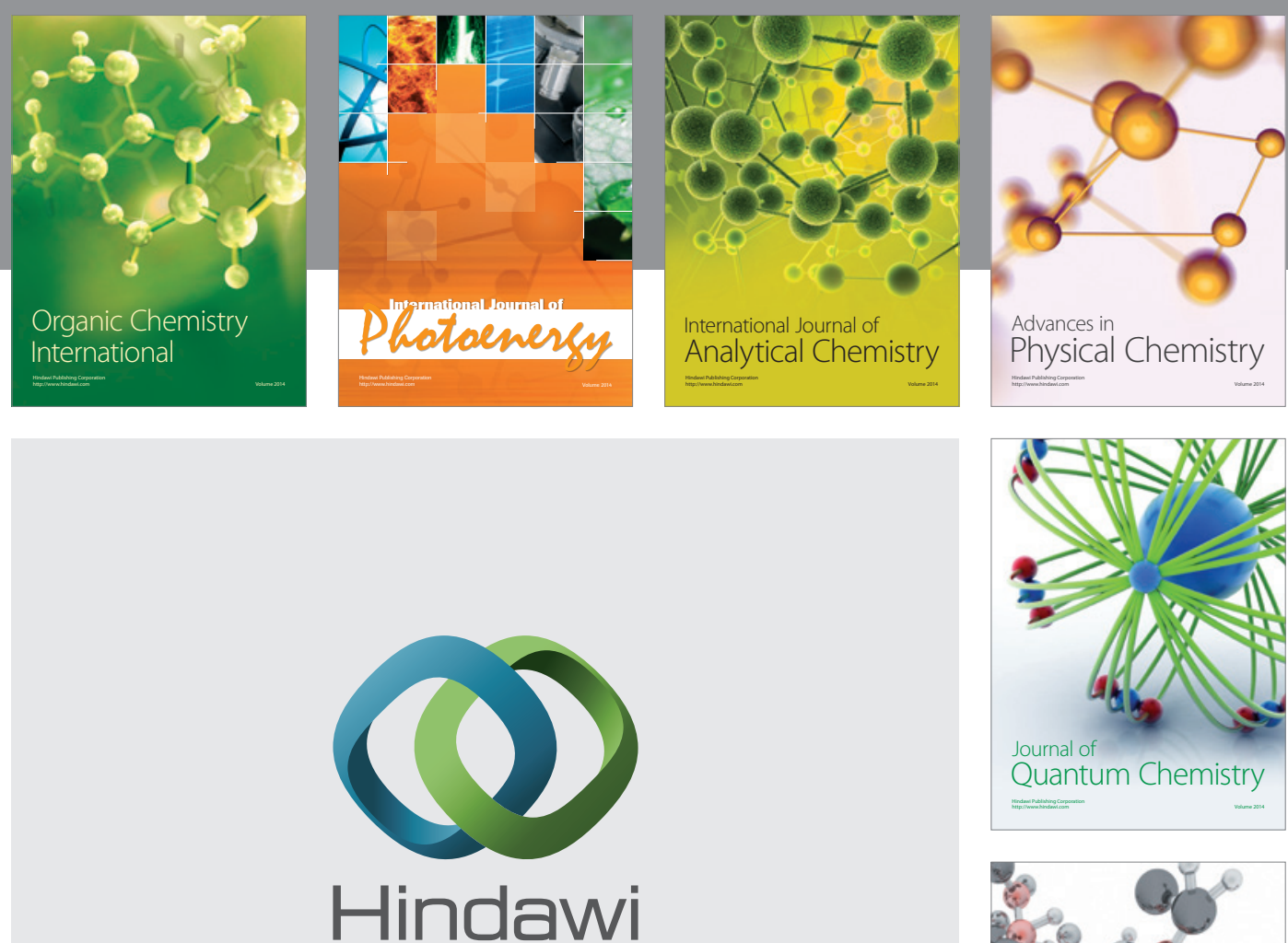

Submit your manuscripts at

http://www.hindawi.com

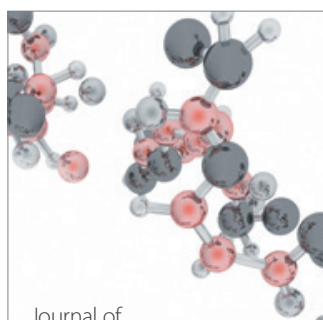

Analytical Methods

in Chemistry

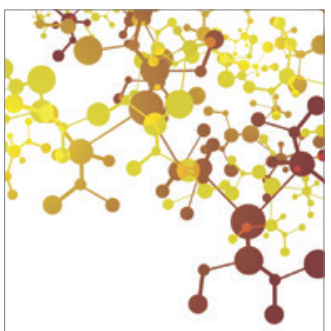

Journal of

Applied Chemistry

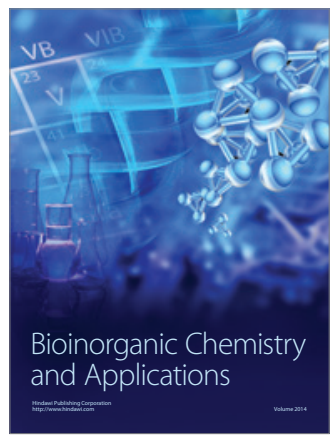

Inorganic Chemistry
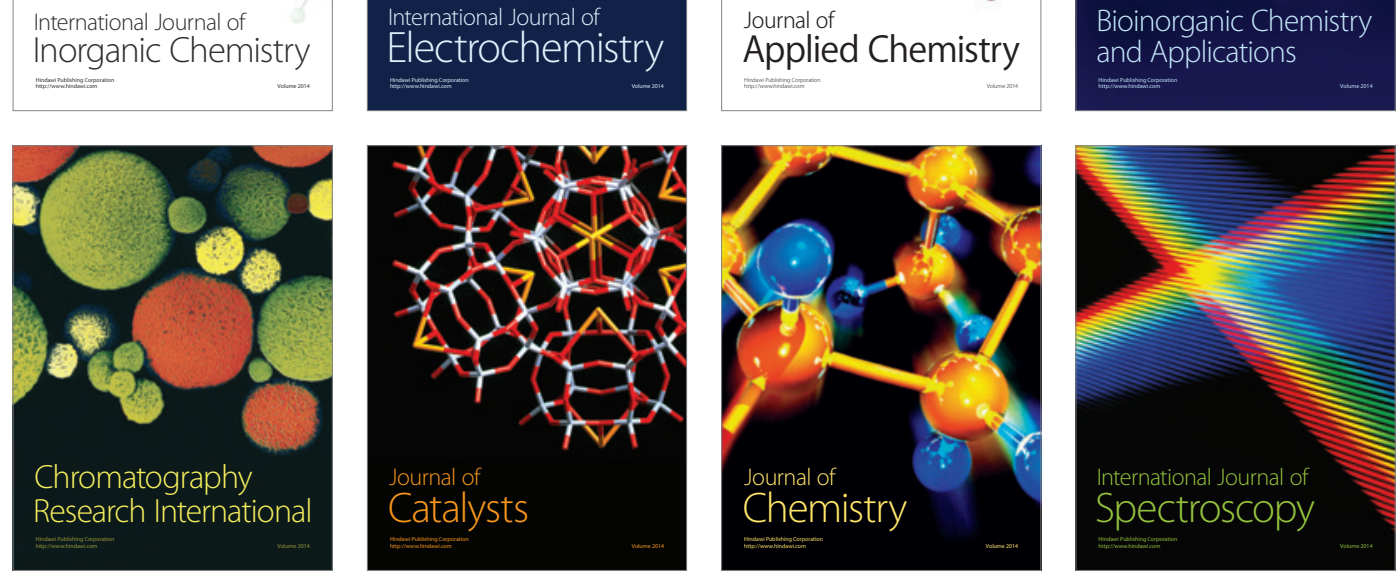